\title{
BALIZAMENTO CONCEITUAL DO MOTION GRAPHIC DESIGN
}

Washington Dias Lessa, PhD.

Escola Superior de Desenho Industrial - ESDI/UERJ

washington.lessa@gmail.com

Isabel Xavier Freire

Escola Superior de Desenho Industrial

PPD-ESDI UERJ

Resumo: O motion graphic design vem se consolidando como área de atuação no campo do design. O processo segue a mesma lógica que leva à caracterização de especializações como o design de livros ou o design de interação, por exemplo. Este artigo tem o objetivo de contribuir para sua conceituação, considerando sua prática e seu posicionamento no mercado. A pesquisa parte da premissa de que o motion graphic design supõe particularidades dadas pela conjunção entre práticas e institucionalizações, tendo em vista: uma circunscrição de tipos de artefatos na cultura material contemporânea; especificidades de linguagem gráfica e as condições tecnológicas de seu exercício.

Palavras-chave: motion graphic design, design de comunicação, linguagem gráfica

\begin{abstract}
The motion graphic design has been consolidating itself as an area of expertise in the design field. This paper aims to contribute to its conceptualization, considering its practice and its position in the market, seeking to offer subsidies that enhance the professional activity. The research assumes that motion graphic design supposes features given by the conjunction between practices and institutionalization, taking into account: specific species of artifacts in contemporary material culture; specific characteristics of graphic language; technological conditions of its practice.
\end{abstract}

Keywords: motion graphic design, communication design, graphic language 


\section{INTRODUÇÃO}

O motion graphic design ${ }^{1}$ vem progressivamente se consolidando como área de atuação no campo do design. O processo segue a mesma lógica que leva à caracterização de especializações como o design de livros ou o design de interação, por exemplo, as quais igualmente se constituem com base da aplicação de know-how projetual a um tipo particular de artefato.

Apesar dessas especializações se equipararem de um certo modo, pois caracterizam-se como áreas do design enquanto campo unificado de conhecimento, cada uma delas guarda suas particularidades. Tanto seu surgimento e formalização quanto as transformações que sofrem, acontecem em contextos históricos singulares, a partir de especificidades tanto externas quanto internas ao campo. São externas as condições tecnológicas, econômicas, de inserção da profissão no mercado, de hábitos e necessidades de consumo, de parâmetros culturais etc; e as especificidades internas ao campo são dadas por configurações de categorias que organizam a prática profissional e a identidade da profissão, envolvendo diretrizes de caráter normativo que dizem respeito a metodologias e a outros aspectos prático-projetuais -, a parâmetros de inserção social da profissão, a critérios do que seja um design de qualidade etc.

O design de livros, por exemplo, relaciona-se à invenção da tipografia - a primeira mecanização do artesanato, segundo McLuhan (1969), que impõe a necessidade de projeto face à obsolescência forçada do trabalho dos copistas -, antes mesmo da caracterização do design moderno a partir do século XVIII. Mas o modelo do livro moderno, estabelecido por Aldus Manutius no Renascimento, vai passar por várias reformulações até chegar ao livro de hoje. O design de interação, o outro exemplo mencionado, só começa a se constituir nos anos 1980, quando a tecnologia computacional passa a ser aplicada em artefatos para o consumo em geral. Em termos tecnológicos a especialização dialoga com a engenharia de softwares, que introduz novos parâmetros para a prática do design; e o seu desenvolvimento leva à introdução de novas premissas para o projeto, como, por exemplo, a categoria de experiência do usuário, que vem destronar a funcionalidade de uso do design modernista. E há o momento em que, com o ebook, passam a relacionar-se o design de interação e o design de livros.

Dado o caráter múltiplo e cambiante do campo do design, o esforço de conceituá-lo em seus vários aspectos é um dos focos da atividade acadêmica. Mas também no mercado surgem iniciativas nesse sentido, abrangendo implícita e/ou explicitamente tanto enquadramentos técnicos quanto articulações que visam apresentar uma identidade profissional. Independentemente da validade que essa conceituação não rigorosa tem para a condução da prática, ela tende a ser fragmentada e descoordenada. Diferentemente, a conceituação desenvolvida segundo parâmetros acadêmicos deve buscar trabalhar com rigor as dimensões categoriais e terminológicas, voltando-se para uma compreensão real da prática e de seu posicionamento no mercado, assim como buscando oferecer subsídios que potencializem a atividade profissional. Nesse sentido, não se pode ignorar a

\footnotetext{
${ }^{1}$ Neste texto, em conformidade com o uso corrente, serão utilizados como sinônimos motion graphic design e motion graphics.
} 
necessidade de uma "conversa" entre os dois âmbitos, para que a formalização do conhecimento, que se faz necessária para as atividades de ensino e pesquisa, seja adequada à complexidade do mercado e das práticas profissionais concretamente existentes.

Partindo de dados e caracterizações que podem ser encontrados em instâncias acadêmicas e profissionais de reconhecimento da prática projetual de motion graphics, este artigo se estrutura em cinco partes: 1) esta introdução, que apresenta alguns pressupostos para a caracterização do motion graphic design como área de atuação profissional; 2) identificação de questões presentes em algumas de suas definições na bibliografia especializada recente; 3) levantamento dos tipos de projeto de motion graphic design considerados em premiações de associações de promoção profissional do design; 4) recuperação dos marcos históricos que pontuam o processo de surgimento e desenvolvimento da área; 5) conclusão.

\section{QUESTÕES PRESENTES EM ALGUMAS DEFINIÇÕES DE MOTION GRAPHIC DESIGN}

Considerando a bibliografia recente sobre motion graphic design, foram selecionadas algumas definições, com o intuito de caracterizar questões que afloram na busca de especificidades. Seguem as definições, por ordem cronológica de edição², nas quais sublinhamos os tópicos que serão comentados:

Frantz, M. Changing Over Time: The Future of Motion Graphics $\left(2003^{3}\right)$

Definir design gráfico é problemático, porém não é tão problemático quanto definir um ramo do design gráfico geralmente referido como motion graphics. (...) Irei definir motion graphics como visuais projetados nãonarrativos e não-figurativos que mudam ao longo do tempo. (...) A distinção de não-narrativo e não figurativo é feita para separar o motion graphics da definição de animação ou filme. (...) Um vídeo ou filme de um objeto real em movimento não seria considerada motion graphics, a menos que fosse integrada com elementos do design, como tipografia, formas ou linhas.

Krasner, J. Motion graphic Design (2008: p. xiii)

Fazer design no tempo e espaço apresenta uma gama de desafios únicos e criativos que combinam a linguagem do design de comunicação tradicional com a linguagem visual dinâmica do cinema em um sistema híbrido de comunicação.

Velho, J. Motion Graphics: linguagem e tecnologia (2008: p.19)

(...) uma área de criação que permite combinar e manipular livremente no espaço-tempo camadas de imagens de todo o tipo, temporalizadas ou não (vídeo, fotografias, grafismos e animações), juntamente com musica, ruídos e efeitos sonoros.

\footnotetext{
2 Tradução nossa de Betancourt, Frantz, Krasner e Shaw.

${ }^{3}$ Não é possível designar uma página uma vez que o documento está disponível online sem numeração de página, no endereço: www.mattfrantz.com/thesisandresearch/motiongraphics.html
} 
Souza, L. Música em movimento (2012: p. 18)

\begin{abstract}
Na busca por uma definição do termo é importante observar esta linguagem sob a ótica de dois pontos de vista: o técnico, descrevendo o motion graphics como uma aplicação mista de variadas tecnologias de computação gráfica e vídeo digital; e o conceitual, como um espaço para o desenvolvimento de um projeto gráfico por meio de imagens em movimento. Portanto, a linguagem motion graphics se caracteriza pela composição visual e manipulação de imagem em movimento por computador, permitindo, assim, animar diferentes tipos de representação audiovisual (vídeos, fotos, tipografia e elementos gráficos).
\end{abstract}

Betancourt, M. The History of Motion Graphics (2013: p. 10)

\begin{abstract}
A gama de práticas artísticas e comerciais que coletivamente podem ser chamadas de "motion graphics": música visual, animação abstrata, broadcast design, tipografia cinética e aberturas de filmes demonstram uma história de fontes comuns nas quais imagens em movimento são tratadas como um meio gráfico, e não um substituto para o teatro dramático ou histórias narrativas.
\end{abstract}

Shaw, A. Design for motion (2016: p.10)

\begin{abstract}
Motion Graphics é um campo que está surgindo que combina mídia em movimento e gráfica. Mídia em movimento inclui disciplinas como animação, filme e som. A qualidade definidora é mudança ao longo do tempo. Mídia gráfica inclui disciplinas como design gráfico, fotografia e pintura.
\end{abstract}

Observa-se inicialmente a tendência a não distinguir com clareza elementos de linguagem audiovisual - "música visual, animação abstrata, tipografia cinética" - e áreas de projeto/tipos de artefato - "broadcast design; aberturas de filme" (Betancourt). Mas algumas definições se referem especificamente às características da linguagem do motion graphics: manipulação "no espaço-tempo [de] camadas de imagens de todo o tipo, temporalizadas ou não (vídeo, fotografias, grafismos e animações), juntamente com musica, ruídos e efeitos sonoros" (Velho); "vídeos, fotos, tipografia e elementos gráficos" (Souza). De todo modo, a linguagem se caracteriza pela combinação de elementos heterogêneos.

Algumas definições indicam a colaboração entre disciplinas - "design gráfico, fotografia e pintura"(Shaw), por exemplo -, com destaque para a convergência cinema/design de comunicação (e seu contexto): "linguagem do design de comunicação (...) com a linguagem visual dinâmica do cinema" (Krasner); "mídia em movimento (...) mídia gráfica" (Shaw); "imagens em movimento (...) tratadas como meio gráfico" (Betancourt).

Ao mesmo tempo a necessidade de diferenciação entre a área de cinema/animação e o motion graphics pode levar a equívocos, como o de caracterizálo como "não-narrativo" (Frantz). O fato é que a animação tradicional e seus personagens se inscreve no âmbito da narração audiovisual própria do cinema, homóloga à literatura, enquanto o artefato de motion graphics se propõe, mesmo que seja com um apoio narrativo, a transmitir informações. Isso fica claro na formulação de 
que "um vídeo ou filme de um objeto real em movimento não seria considerada motion graphics, a menos que fosse integrado com elementos do design, como tipografia, formas ou linhas" (Frantz).

O risco desta confusão diminui se atentamos para o fato de que os mesmos termos - filme e animação - referem-se tanto a técnicas, que são utilizáveis em um artefato de motion graphics, quanto às obras fílmicas ou de animação.

A prática de motion graphic design se daria segundo "dois pontos de vista: o técnico, [envolvendo] uma aplicação mista de variadas tecnologias de computação gráfica e vídeo digital; e o conceitual, como um espaço para o desenvolvimento de um projeto gráfico" (Souza). A definição destaca, assim, dois polos: um ligado à técnica e outro ligado ao tipo de artefato. As questões de linguagem, já mencionadas acima e referidas pelo autor com o termo "composição visual", podem ser consideradas como um terceiro polo. Artefato, linguagem e tecnologia se colocariam, assim, como três parâmetros de inteligibilidade do motion graphic design.

Finalmente vale observar que, ao indicar que o âmbito tecnológico se caracteriza por "tecnologias de computação gráfica e vídeo digital" e "manipulação de imagem em movimento", Souza privilegia apenas aqueles artefatos de motion graphics produzidos no período em que a tecnologia digital torna-se hegemônica.

O item a seguir apresenta tipos de artefatos que são considerados, por instituições da área do design, como característicos da especialização motion graphic design hoje. 0 item 4 busca recuperar, a partir de referências históricas, como a especialização vai se constituindo tendo em vista os três parâmetros identificados nas definições de motion graphics.

\section{TIPOS DE PROJETO DE MOTION GRAPHIC DESIGN CONSIDERADOS POR INSTITUIÇÕES QUE MANTÊM PREMIAÇÕES EM DESIGN}

Considerando, num corte sincrônico, o momento atual, buscou-se um parâmetro de identificação dos tipos de artefatos relacionados ao motion graphic design. Para isso, foram levantadas: a) categorias utilizadas por premiações de design, no Brasil e no exterior, que reconhecem a especialização: b) categorias utilizadas por premiações internacionais voltadas para as produções de cinema e televisão.

Em relação às instituições específicas da área de design, foram analisados os acervos documentais de duas associações, uma norte americana e a outra brasileira. São elas a AIGA, the professional association for design, anteriormente conhecida como American Institute of Graphic Arts, com suas seleções anuais; e a ADG Associação de Design Gráfico, com suas seleções bianuais.

A AIGA é a mais antiga organização de membros profissionais de design, tendo sido criada em 1914. Promove anualmente premiações, mantendo um arquivo com os vencedores desde 1924. Constam do arquivo vários tipos de produtos, tais como: book design, experience design, package design, promotional design and advertising, brand and identity systems design e motion graphics. Categorias como book design e advertising possuem mais de seis mil itens; package design e brand and identity systems design possuem cerca de mil, enquanto categorias como experience design e motion graphics possuem, respectivamente, 205 e 238 itens, pois são categorias mais 
recentes.

O trabalho de motion graphics mais antigo é a abertura produzida em 1964 para o filme Goldfinger, da série de filmes do agente 007. Apesar dessa abertura estar assim classificada, não foi possível identificar se a designação já era utilizada nessa época. Entre 1964 e 1989 só estão arquivados sete trabalhos na categoria. Já no período de 1990 aos dias atuais estão arquivados 231 trabalhos, evidenciando a expansão da atividade possibilitada pelos programas digitais, e a consolidação do motion graphic design como uma área de especialização do design.

É possível identificar diversos tipos de artefatos classificados como motion graphics pela AIGA. Entre eles, os mais recorrentes são: identidade visual de canal de televisão, abertura de filme, abertura de programa para televisão, vídeo promocional, campanha publicitária, videoclipe e cenário em vídeo.

Exemplos de outras premiações internacionais que contemplam direta ou indiretamente o motion graphic design são o if Design Award (Alemanha), com a categoria filme/vídeo dentro da disciplina comunicação, e o IDA, International Design Awards (Estados Unidos), com a subcategoria animação, situada em multimídia, que por sua vez é categorizada dentro de graphics.

Quanto à brasileira ADG, a necessidade de incluir artefatos de motion graphics nas suas mostras bianuais começa a surgir a partir do ano 2000, sendo que o processo se desenvolve não sem hesitações quanto à nomenclatura. A instituição começou a selecionar produtos audiovisuais na sua quinta edição (2000), quando introduziu a categoria vídeo e cinema. A oitava edição (2006), passou a usar a categoria design em movimento, e a nona (2009) utilizou design e interfaces audiovisuais. Na décima edição (2013) foi criada a categoria motion design, que se manteve em 2015.

Entre os 37 projetos selecionados em 2013 e 2015 estão presentes diferentes tipos de artefatos, que correspondem às presenças mais frequentes nos arquivos da AIGA: identidade visual de canal de televisão, abertura de filme, abertura de programa para televisão, vídeo promocional, campanha publicitária, videoclipe e cenário em vídeo. Ou seja, os principais tipos de artefato são similares nas premiações das duas instituições, indicando um certo entendimento dos tipos de produtos que são reconhecidos como motion graphics tanto internacionalmente, quanto no Brasil.

Um outro registro no Brasil é o de um concurso recente promovido pelo IED, Instituto Europeu de Design, o IED Brasil + Expo Milão 2015, que apresentou dentro da categoria design gráfico a sub categoria motion graphics. Outras premiações brasileiras, como o Brasil Design Award e o Prêmio Design MCB, não contemplam a categoria.

Considerando, por outro lado, as premiações voltadas para as produções de cinema e televisão, destaca-se o Emmy Awards, principal prêmio da televisão norte americana, que desde 1997 tem uma categoria chamada main title design para reconhecer as melhores aberturas de séries produzidas naquele ano. Entretanto as principais premiações do cinema mundial, como o Oscar e o Golden Globe, não contemplam aberturas dos filmes. Existem também instituições menores, como a SXSW South by Southwest ${ }^{\circledR}$, promotora da SXSW Film Design Awards, voltada para a parceria entre designers e cineastas, que tem uma categoria específica para aberturas 
de filmes.

Nessas premiações, além de uma diversidade de tipos de artefatos, também é possível perceber uma grande diversidade de técnicas e linguagem visual nos artefatos selecionados. Dentre os trabalhos é possível identificar animação digital 2D e 3D de cenários e personagens, stop motion, filmagens, animação de tipografia e elementos gráficos, animação de recortes, rotoscopia entre outros. E isso vem confirmar o caráter heterogêneo da linguagem do motion graphics.

\section{MARCOS NO PROCESSO DE SURGIMENTO E DESENVOLVIMENTO DO MOTION GRAPHIC DESIGN COMO ESPECIALIZAÇÃO}

Os tipos de projeto evidenciados nessa abordagem sincrônica, também podem, de modo complementar, ser caracterizados diacronicamente. Para isso recorremos, entre as fontes disponíveis, a Betancourt (2013) e Velho (2008)

O momento fundador da área de motion graphic design associa-se ao trabalho de Saul Bass. Ele começou sua carreira trabalhando com layout em agências de publicidade e na década de 1950 abriu seu próprio escritório e começou a trabalhar com cinema. Em 1954 foi contratado para fazer o material impresso de divulgação e a abertura para o filme Carmen Jones, de Otto Preminger, configurando os elementos da identidade visual do filme. Conhecedor das realizações da Bauhaus, combinou o texto com o desenho de uma rosa superposto a uma chama em movimento, estabelecendo um contraste marcante com a abertura tradicional, composta, com algumas poucas exceções, por cartelas estáticas com o texto sobre fundo preto.

No trabalho de Bass o projeto se conecta gráfica e conceitualmente à tradição dos filmes experimentais do começo do século $X X$, o que faz com que alguns autores identifiquem aí o começo do motion graphic design. É necessário ter a clareza que esses filmes eram experimentos exclusivamente cinematográficos, ou realizados no âmbito das vanguardas artísticas. Se se considera motion graphics, ou motion design, em geral, abarcando realizações artísticas e comerciais (Betancourt, 2013), pode-se falar em uma confluências dessas duas áreas. Mas em termo de motion graphic design o que se evidencia é uma filiação de linguagem: a influência das vanguardas artísticas no design gráfico modernista e a incorporação do movimento à linguagem praticada por esse design gráfico.

Um dos primeiros registros da utilização do termo motion graphics foi o nome da empresa Motion Graphics Incorporated, fundada por John Whitney em 1960 (id., 2013). Whitney trabalhava com experimentações com imagem em movimento e tecnologia para criar filmes abstratos, assim como animações para programas de televisão e curtas de música. Trabalhou com Saul Bass na abertura de Vertigo, criando as formas espirais utilizadas na abertura. Whitney falou sobre "motion graphics" em 1962 na Catalina Design Conference:

Quando uma abertura de filme na tradição estabelecida por Saul Bass possui uma articulação interessante, geralmente obtém sucesso como abertura. (...). Essa questão da articulação é o que chamo de Motion Graphics e é claramente um novo problema no campo do design; tão pouco explorado que designers devem explorá-lo com cuidado e um senso de aventura. 


\begin{abstract}
Aberturas de filmes tem sido vendidas para clientes; vendidas, aprovadas e pagas, que devem ter parecido maravilhosas no storyboard. Mas o storyboard é no máximo uma série de desenhos estáticos que sugerem ou indicam o movimento que foi concebido. Se na produção essa ação não é realizada, ou foi pouco imaginativa desde o início, storyboards muito impressionantes do ponto de vista do design gráfico podem ainda ser design gráfico estático quando chegam nas telas - dizemos que o trabalho não é dinâmico. Podem ser bons gráficos - mas não são bons Motion Graphics. (id.: 129 - tradução nossa)
\end{abstract}

Percebe-se, então, que na década de 1960, a partir dessa reconceituação das aberturas de filmes, iniciada por Saul Bass, o campo do motion graphics começou a se formar e ser entendido como uma área do design. Whitney entende a nova área como próxima ao design gráfico, porém com a especificidade do movimento, considerando a importância que este assume em um bom trabalho de motion graphics.

Simultaneamente ao desenvolvimento dessas aberturas de filmes, a televisão se expande como mídia, mudando a relação das pessoas com a imagem em movimento: não só tinham acesso a ela em suas casas, como tinham o controle do que poderiam escolher ver. Os canais de televisão precisavam se diferenciar uns dos outros e para isso recorreram ao design de comunicação. O canal CBS foi o primeiro a adotar essa estratégia, com peças gráficas unificadas incluindo impresso, comerciais na TV, nas câmeras e nas placas.

De acordo com Meggs e Purvis (2009), nos anos 1950 os sistemas de identidade visual, recontextualizando o papel da marca ou do símbolo, passaram a unificar as peças de comunicação da empresa, visando a construção coerente de sua imagem. A CBS foi uma das pioneiras no design de identidade corporativa e a marca é considerada uma das mais bem sucedidas do século XX (id.). A marca da CBS, assim como diversas outras criadas na época, seguiam a ideia de que marcas deveriam ser "reduzidas a formas elementares que fossem universais, visualmente únicas e estilisticamente atemporais."(id.: p. 529) E colocava-se o desafio de incorporar o movimento à identidade visual. A partir daí consolida-se esta outra frente do motion graphic design. As condições são homólogas às das aberturas de filmes: os dois tipos de artefato trabalhavam a questão da identidade visual, relacionada a um filme ou a um canal de televisão, e tinham como principal referência o design modernista.

Um desdobramento da identidade dos canais veio com a elaboração de aberturas para os seus programas, que tinham a mesma lógica de linguagem das aberturas de filmes, que se estabelecem como padrão a partir de 1964. Nessa mesma época a publicidade começa a fazer parte da programação, são criados os blocos de comerciais que se intercalam na programação, ampliando mais a possibilidade de atuação do motion graphic designer.

A década de 1980 traz o videoclipe como mais uma frente do motion graphic design. Marco importante é a inauguração, em 1981, do canal de televisão MTV, que veiculava $24 \mathrm{~h}$ horas por dia uma programação composta apenas de videoclipes. Anteriormente, o videoclipe costumava apresentar apenas a imagem do cantor interpretando a música, e mesmo persistindo a utilização apenas da linguagem cinematográfica, a partir do início da década alguns videoclipes passam a associar a música a novas expressões visuais, com cortes rápidos, muitas imagens, utilização de 
elementos gráficos e mesmo de tipografia. Essa busca de sintonia entre a identidade do artista e o público jovem possibilita a utilização e o desenvolvimento da linguagem do motion graphic design.

A década de 1990, por seu turno, é marcada pela difusão do computador como ferramenta. Créditos de filmes, videoclipes, comerciais, séries de televisão e mesmo filmes passam a ser elaborados/editados em programas como Adobe Premiere e Adobe After Effects, lançados em 1991 e 1992, respectivamente (Betancourt, 2013), acessíveis tanto a grandes empresas quanto a pequenos estúdios. Esses programas possibilitavam a manipulação de vídeo e criação de efeitos de modo mais rápido e prático, em um único sistema, facilitando a conjunção de técnicas tais como cinema, os diversos tipos de animação, sínteses formais digitais etc, e ampliando as possibilidades de edição etc.

Esses novos parâmetros tecnológicos tornaram mais fácil e barata a produção de imagens e a pós produção audiovisual. Câmeras DSLR ${ }^{4}$ de captura de vídeo de alta qualidade, com características semelhantes a câmeras mais caras, eram compatíveis com orçamentos menores, facilitando tanto o trabalho de pequenas produtoras como a criação de vídeos com qualidade técnica por não profissionais.

É justamente nesse cenário que as aberturas de filmes passam por um renascimento criativo, destacando-se da produção mais convencional dos anos 1970/80. Isso ocorre principalmente a partir de 1995, com a abertura criada por Kyle Cooper para o filme "Se7en". O desenvolvimento tecnológico e barateamento da pósprodução da imagem em movimento foi um dos fatores que possibilitou que os créditos iniciais voltassem a ser produzidos de modo mais intenso e integrado com os filmes.

De acordo com Krasner (2008), as novas tecnologias também facilitaram e baratearam a projeção de imagens em movimento, assim como a produção de telas de grandes dimensões. Isso possibilitou que o motion graphic design também pudesse ser mobilizado para agenciamentos ambientais, tais como shows, exposições, vitrines, lojas, festas, entre outros.

Todo este movimento de facilitação também é captado pelo avanço tecnológico da internet, cada vez mais rápida, possibilitando o download de grandes arquivos, como os de vídeo, e assim contribuindo para sua divulgação. Sites como o Youtube, lançado em 2005, possibilitam ao usuário assistir imediatamente os vídeos lá hospedados, facilitando o acesso e a distribuição do material audiovisual, tanto amador quanto profissional. De acordo com Lipovetsky e Serroy (2009: p. 291) "nunca se produziram e se difundiram tantas sequências filmadas", pois as pessoas filmam e divulgam continuamente suas vivências e referências, que podem ser acessadas por um número enorme de pessoas em muito pouco tempo.

No Youtube, além dos vídeos amadores mais simplórios, também existe uma produção mais elaborada, amadora ou profissional, de curtas, videoclipes, séries e animações. E como no caso dos videoclipes e das projeções ambientais, também se encontra nesse meio realizações mais autorais, que se aproximam dos parâmetros próprios do âmbito das artes. O motion graphic design aparece em muitas dessas

\footnotetext{
${ }^{4}$ digital single-lens reflex cameras, máquinas fotográficas profissionais
} 
produções, como por exemplo nos infográficos que são compartilhados diariamente pelas redes sociais sobre os mais diversos assuntos, desde um perigoso vírus de computador $^{5}$ até o sistema educacional nos Estados Unidos 6 .

Finalmente, temos que o motion graphic design faz-se presente no espaço virtual não apenas em vídeos. O movimento coordenado de elementos gráficos, tipografia e imagens vem ganhando importância progressiva em websites, aplicativos e sistemas operacionais de computador ou mobile. Um exemplo é o do sistema operacional Android, do Google. A companhia criou um website ${ }^{7}$ explicando a linguagem visual criada para esse sistema, com o objetivo de orientar profissionais que criam aplicativos para ele, os quais devem ser coerentes com a identidade visual do sistema. "Animação" é uma das principais categorias do site, onde são explicadas as características dos movimentos, como hierarquização dos movimentos e coordenação das animações dos elementos. O site explicita em seu discurso que "movimento cria significado", por isso é importante ser consistente e auxiliar na navegação do usuário.

Isso vem delimitar uma outra área de expansão do motion graphic design, embora este tipo de trabalho não seja contemplado nas premiações da AIGA e da ADG. Dentro da lógica segundo a qual a especialização se conecta a outras áreas e artefatos, pela sua participação em projetos mais abrangentes, essas elaborações de linguagem ainda não são consideradas como artefatos de motion graphic design, pois ainda se caracterizam como técnicas e conceitos utilizados em projetos maiores. $E$, de fato, não se sabe ainda como esta nova situação se integrará no âmbito conceitual do motion graphic design.

\section{CONCLUSÃO}

Esta investigação sobre motion graphic design partiu do pressuposto que sua constituição como área de conhecimento profissional - como no caso de outras áreas - supõe particularidades dadas pela conjunção entre condições de trabalho, práticas e movimentos de institucionalização/consolidação nos contextos onde a especialização se mostra. E isto considerando tanto momentos históricos singulares quanto suas dinâmicas de desenvolvimento e transformação.

Partindo de algumas definições atuais de motion graphics, foi possível identificar questões que apontam para três ordens de parâmetros de inteligibilidade da área. Referem-se: a) à caracterização utilitária e cultural de tipos de artefato no âmbito da cultura material contemporânea; b) às condições tecnológicas de existência e produção desses artefatos; c) às referências de linguagem projetual - audiovisual, no caso - e às poéticas que se constituem e são exercidas na elaboração dos artefatos.

Quanto às questões associadas ao tipo do artefato, primeiramente - e evidentemente - destaca-se a ocorrência em contextos audiovisuais. Um segundo aspecto é o de serem artefatos sem autonomia, que fazem parte de artefatos mais complexos: uma abertura de um filme ou de televisão está subordinada ao filme ou programa correspondentes; um cenário de show só ganha sentido preciso em cena; as

\footnotetext{
${ }^{5}$ Stuxnet: Anatomy of a Computer Virus de Patrick Clair

${ }^{6}$ Waiting For 'Superman' - Infographic de Ryan Honey

${ }^{7}$ http://www.google.com/design/spec/material-design/introduction.html
} 
vinhetas dos canais de televisão fazem parte de um programa de branding; um comercial de uma campanha dialoga com impressos e outras mídias dessa campanha, etc. Nessa relação de dependência, ganham sentido tendo em vista a transmissão de informações e/ou como elementos de identidade visual ou audiovisual.

Conforme indicado no item 4, o movimento coordenado de elementos gráficos, tipografia e imagens vem ganhando importância progressiva em websites, aplicativos e sistemas operacionais de computador ou mobile. Embora ainda não se caracterizem como artefatos de motion graphics, são, sem dúvida trabalho em motion graphic design, mobilizando questões de linguagem e condições tecnológicas.

Considerando as questões associadas à tecnologia, a condição fundamental da especialização é dada pelo próprio cinema; e a condição para sua expansão é dada pela tecnologia digital. Mesmo que as aberturas de filme especiais, primeiros artefatos de motion graphic design -só tenham surgido a partir dos anos 1950, elas mobilizam referências da linguagem audiovisual desenvolvida, a partir da tecnologia do cinema, pelas vanguardas das primeiras décadas do século XX. No outro extremo, a tecnologia digital promove uma enorme confluência de técnicas: a edição de vídeo é potencializada e associa-se ao trabalho com formas e tipografia. Ao mesmo tempo permanece um diálogo com técnicas analógicas, como a animação tradicional, o stop motion etc. E nesse novo marco tecnológico se amplia enormemente a produção em motion graphics.

No entanto, um perspectiva como a de Souza, cuja reflexão parte da realidade digital, não deixa ver que a linguagem visual disponibilizada pelos novos programas não nasce com eles, sendo adaptada a partir de uma tradição que conjuga experimentação artística do começo do século XX e o design gráfico moderno.

Considerando as questões associadas à linguagem visual, temos que a lógica da colagem e da fotomontagem, praticada no dadaísmo, construtivismo e surrealismo, se contrapõe à tradição do quadro renascentista, conceituado como cena vista através de uma janela (cf. Alberti), a qual se atualiza com o enquadramento das câmeras fotográfica e cinematográfica (Lessa, 2013). A justaposição de imagens, formas abstratas, tipografia, áreas de cor - camadas de elementos heterogêneos - torna-se uma referência para o design gráfico moderno, o qual preside o desenvolvimento do trabalho fundador de Saul Bass. E esse modelo continua valendo como referência conceitual e visual das "colagens" que incorporam, em artefatos de motion graphics, também animações tradicionais e fragmentos de imagem em movimento, por exemplo, ou das montagens "picotadas" do videoclipe.

As questões da linguagem do motion graphic, por outro lado, podem levar a um "rompimento" de sua adequação ao design. Se é encarada em sua autonomia e potencialidade expressiva, possibilita experimentações mais autorais, não comprometidas com o mercado. Este artefato não comercial é designado graphic film por Sheffield (2007).

\section{REFERÊNCIAS}

ACERVO AIGA. Disponível na internet por http em <http://designarchives.aiga.org/> Acesso em março, 2016. 
BETANCOURT, M. The History of Motion Graphics. EUA: Wildside Press, 2013.

CONE, J. Interview: Motion design and the Google identity, 2015. Disponível na internet por http em <http://motionographer.com/2015/11/09/interview-motiondesign-and-the-google-identity> Acesso em março, 2016.

CONE, J. How Google uses motion design to make tangible tech, 2015. Disponível na internet por http em < http://motionographer.com/2015/01/05/how-google-usesmotion-design-to-make-tangible-tech> Acesso em março, 2016.

FRANTZ, M. Changing over time: The future of Motion Graphics, 2003. Disponível na internet por http em <www.mattfrantz.com/thesisandresearch/motiongraphics.html> Acesso em novembro, 2014.

HORAK, Jan-Christopher. Saul Bass: Anatomy of film design. EUA: University Press of Kentucky, 2014.

KRASNER, J.S. Motion graphics design: applied history and aesthetics. Boston: Focal Press, 2008.

LESSA, W.D. O design de comunicação e a fotografia. Em SZANIECIECKI, Bárbara et allii (org.). Dispositivo fotografia e contemporaneidade. Rio de Janeiro: Nau, 2013 (pp. 5881).

LIPOVETSKY, G.; SERROY, J. A tela global, mídias culturais e cinema na era hipermoderna. Porto Alegre: Editora Sulina, 2009.

MASCARELLO, F. (org.). História do cinema mundial. Campinas: Papirus Editora, 2012.

MACLUHAN, M. Os meios de comunicação como extensão do homem. Trad. Décio Pignatari. São Paulo: Editora Cultrix, 1969.

MACVAL, L.; LUCCHESI, P. (org.). 11 ${ }^{\text {a }}$ Bienal Brasileira de Design Gráfico. São Paulo: Blucher, 2015.

MEGGS, P.B.; PURVIS, A.W. História do design gráfico. São Paulo: Cosac Naify, 2009.

SHAW, A. Design for motion: Fundamentals and Techniques of motion design. New York: Focal Press, 2016

SHEFFIELD, Adam. Graphic Film, A new genre of moving image. 2007. Dissertação (mestrado) - Auckland University of Technology, Auckland, Nova Zelândia, Master of Art and Design.

SOUZA, L. Música em movimento: a linguagem motion graphics nos videoclipes brasileiros (1990-2010). 2012. Dissertação (mestrado) - Instituição de Ensino:

Universidade Municipal De São Caetano Do Sul. Biblioteca Depositária: USCS, São Caetano do Sul. Curso de Pós-graduação em Comunicação.

VELHO, J. Motion Graphics: linguagem e tecnologia - Anotações para uma metodologia de análise. 2008. Dissertação (mestrado). - ESDI Escola Superior de Desenho Industrial, UERJ Universidade Estadual do Rio de Janeiro, Rio de Janeiro, Curso de Pós-graduação em Design. 